\title{
Squamous cell carcinoma of the body of the uterus
}

\author{
HANNA BARNETT ${ }^{1}$ \\ From the Department of Pathology, South London Hospital for Women, Clapham, London
}

SYNOPSIS A case of primary squamous cell carcinoma of the body of the uterus is reported. The number of authentic cases of this tumour which meet the rigid criteria referred to is extremely small. The histological findings are described in detail and some aetiological considerations are mentioned briefly. Certain special aspects of the diagnosis are discussed.

The incidence of primary squamous cell carcinoma of the body of the uterus is extremely rare. Fluhmann (1928) formulated the following conditions which must be met before the diagnosis can be considered as established. 1 There must be no co-existing adenocarcinoma. 2 There must be no connexion between the tumour and the squamous epithelium of the cervix. 3 The absence of a primary growth in the cervix must be established conclusively. Following

'Present address: Department of Pathology, Lewisham General Hospital, Lewisham High Street, London S.E.13.

Received for publication 23 March 1965. these rigid criteria, only five cases were accepted by Fluhmann. Two further cases were described by Wahi and Jain (1949) and by Chu, Lepow, and Godsick (1958). Peris, Jernstrom, and Bowers (1958) published another case and reviewed the literature. The prerequisites for the diagnosis which were formulated by Peris exclude Fluhmann's first criterion, consequently his list of 25 cases published up to 1958 includes tumours which contained both squamous and columnar malignant elements. One further case was published by Mazzella (1963). The following case meets Fluhmann's full requirements.

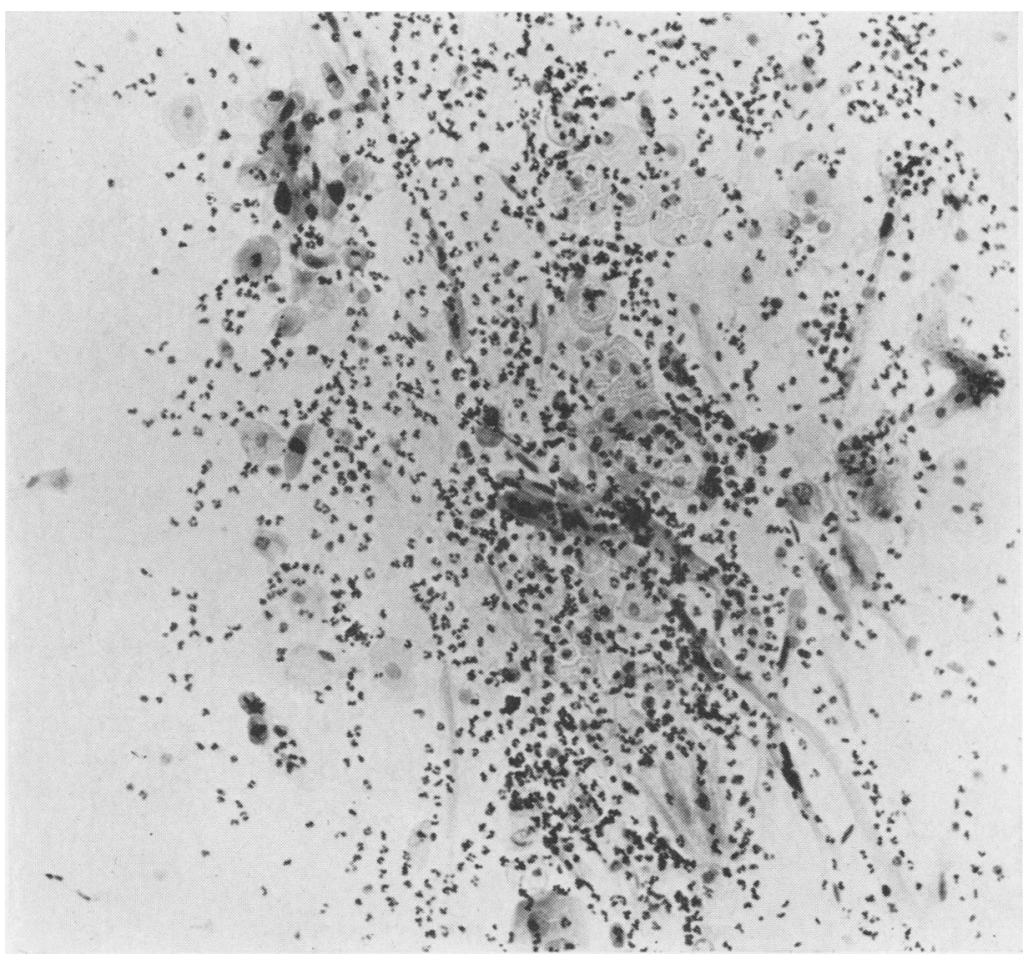

FIG. 1. First cervical smear: many extremely atypical squamous cells. Haematoxylin and eosin $\times 160$. 


\section{CASE REPORT}

A married multiparous woman aged 59 presented with a history of occasional very slight vaginal bleeding for three months. Some discharge was also noted. The menopause had occurred 14 years previously and she had had no bleeding since till the present episode. She was an apparently healthy woman with nothing remarkable in her previous history or family history. Vaginal examination revealed no abnormalities; the cervix appeared healthy, the uterus was small. Routine cervical and vaginal smears were taken. These smears showed a moderate number of extremely atypical squamous cells which were suspicious (Fig. 1) and a cone biopsy was requested. The patient was admitted 10 days later for curettage and biopsy. No abnormalities were found at operation. The uterine cavity measured $6 \mathrm{~cm}$., the curettings were scanty but an adequate cone biopsy was taken. Histological examination of the curettings revealed the presence of blood clot and strips of markedly atypical squamous epithelium only (Figs. 2, 3). The cone was sectioned serially, and the squamous epithelium showed minimal atypia only. The patient was discharged and followed up. On her first follow-up visit six weeks later no further vaginal bleeding had occurred. Smears were repeated and these again revealed the presence of abnormal squamous cells (Fig. 5a). The patient was advised to undergo a hysterectomy but she refused. She was seen at frequent intervals during the following seven months; slight vaginal 'spotting' persisted but no other abnormalities were evident on vaginal examination. The smears consistently showed abnormal squamous cells $\stackrel{0}{9}$ (Fig. 5). (At no time were any abnormal columnar cells 0 found in the smears.) The patient was finally persuaded $\frac{C}{O}$ to undergo hysterectomy preceded by the application of $\overline{\frac{\sigma}{3}}$ radium at another hospital. Before the insertion of the $\vec{\Phi}$ radium $(40 \mathrm{mg}$. in intrauterine tubes, $35 \mathrm{mg}$. in a cervical $\bigcirc$ box, $15 \mathrm{mg}$. in the vagina for 30 hours) a fractional $ै$ curettage was done and multiple cervical biopsies were $\vec{\theta}$ taken. This material was reported as showing chronic inflammatory changes only in the cervix; the curettings $\vec{\omega}$ consisted of keratin debris, blood clot, and strips of $\stackrel{\omega}{\circ}$ squamous epithelium showing marked atypia (Fig. 6).응 Having thus excluded an invasive squamous carcinoma? of the cervix, the patient returned to this hospital 10 days $\infty$ later for a total hysterectomy and bilateral salpingo- 9 oophorectomy, after one dose of radium only. At operation a fundal growth infiltrating the entire thickness of the wall was found. Post-operative recovery was good, 으 and a course of high-voltage radiotherapy was given. The patient is well four months later.

\section{PATHOLOGY}

FIRST CURETTINGS AND CONE BIOPSY The material was very scanty, and consisted of blood clot and a $\mathscr{\bullet}$ few strips of squamous epithelium showing varying. degrees of nuclear atypia (Figs. 2, 3). Two glands lined by columnar epithelium are incorporated in one

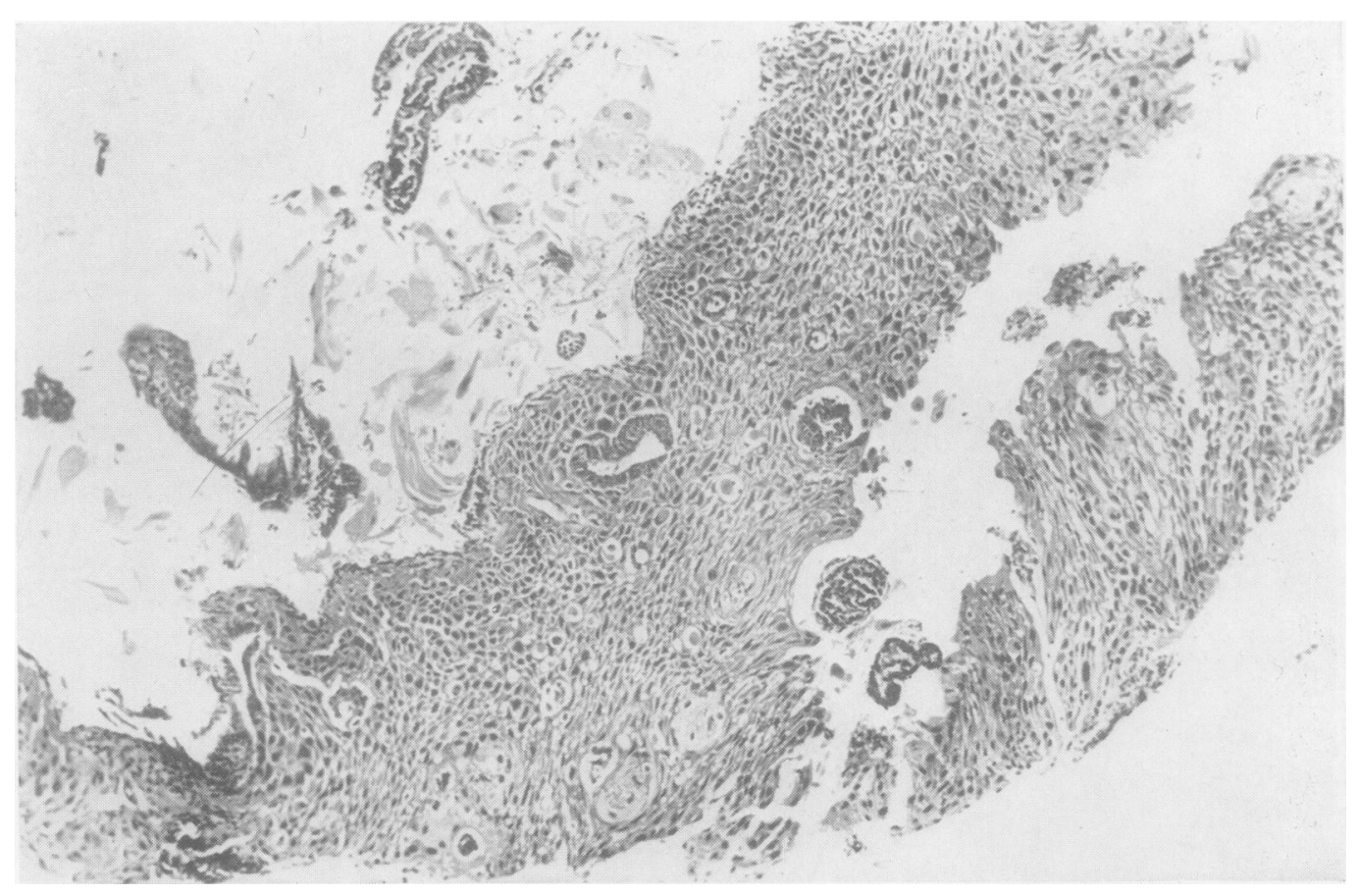

FIG. 2. First curettings: a strip of atypical squamous epithelium. Haematoxylin and eosin $\times 100$. 


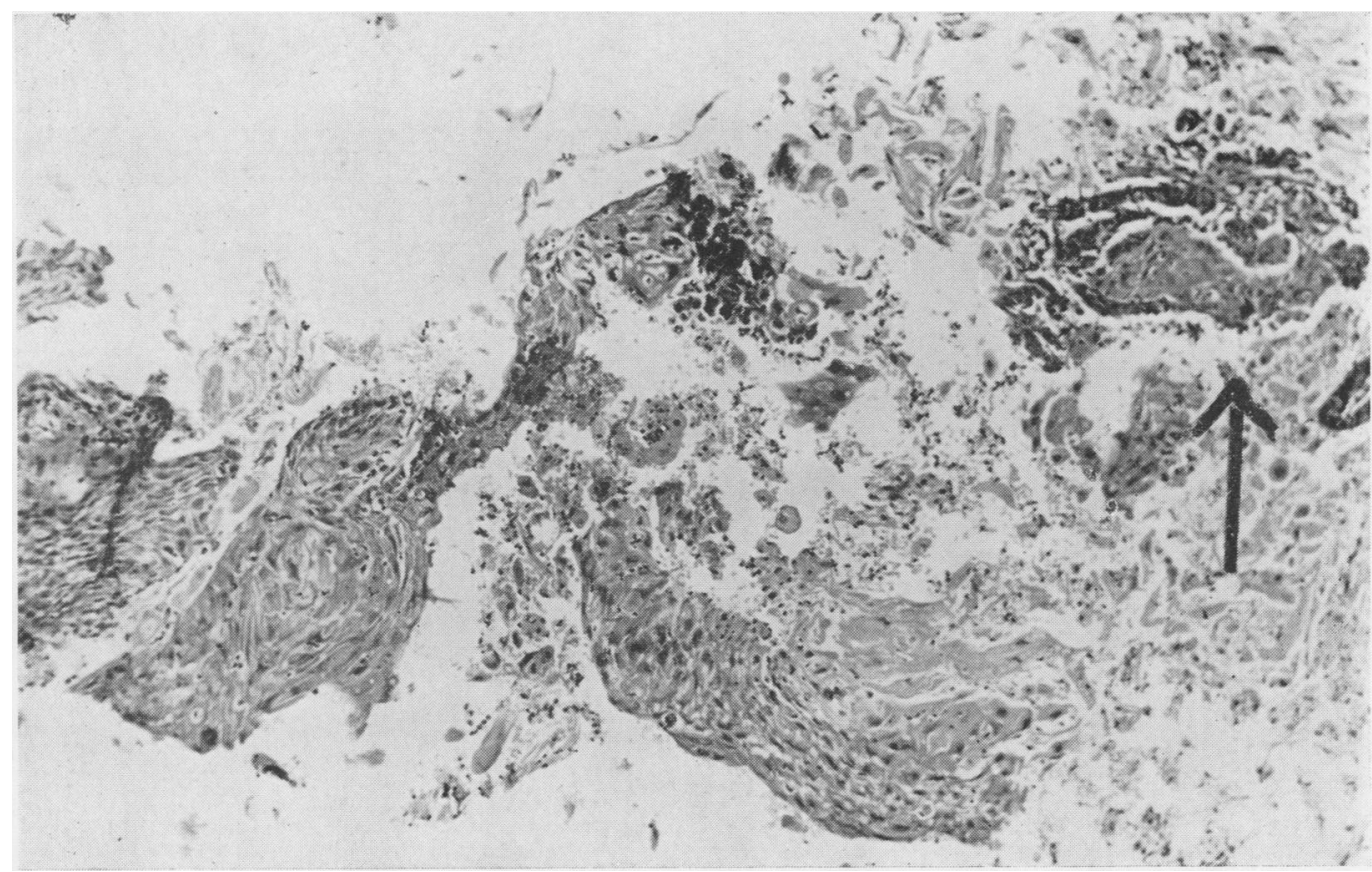

FIG. 3. First curettings: nuclear atypia is more marked. An area resembling adenoacanthosis (arrow). Haematoxylin and eosin $\times 100$.

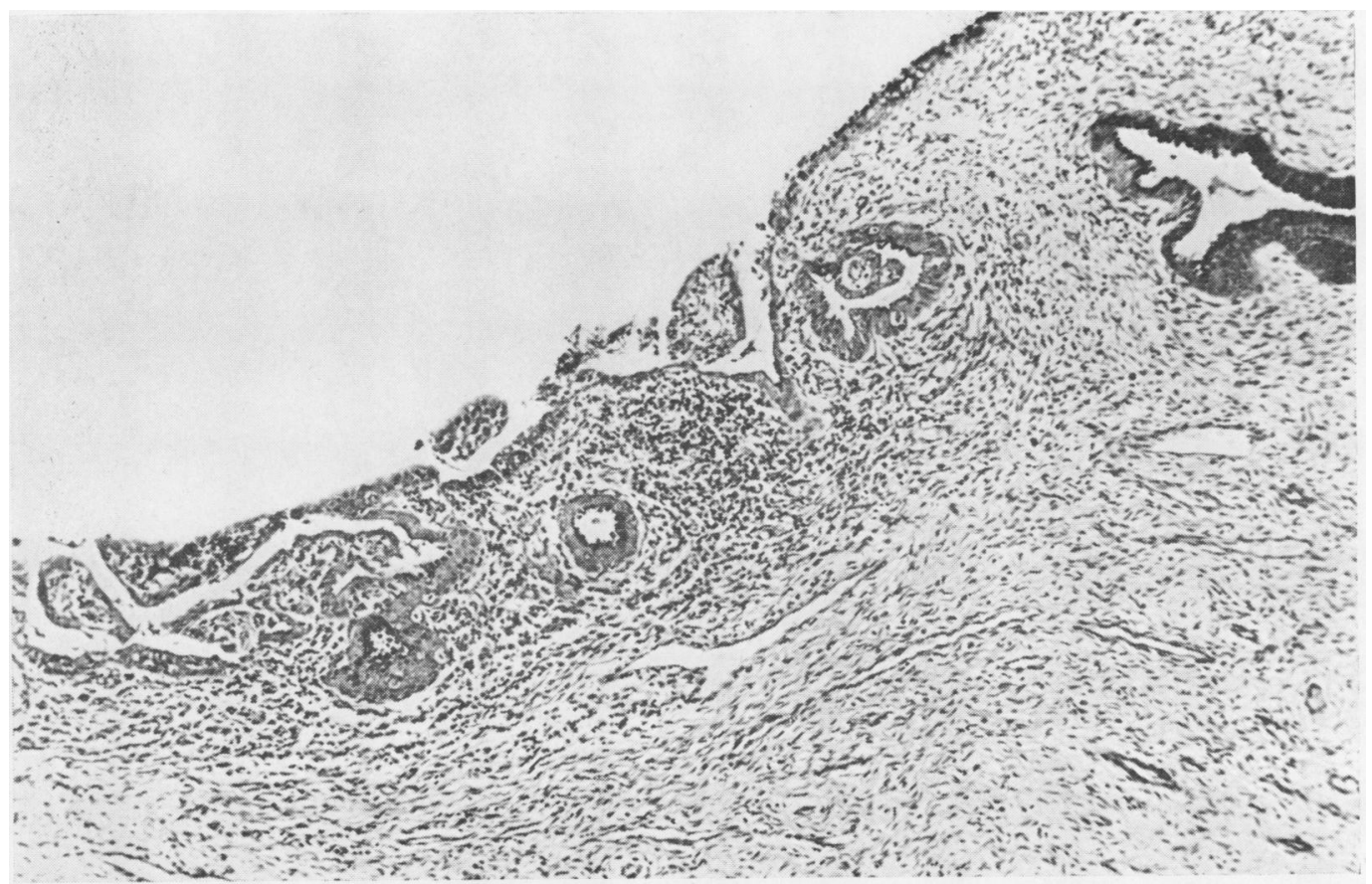

FIG. 4. First cone biopsy: chronic inflammatory changes. Endocervical canal lined by columnar epithelium. Haematoxylin and eosin $\times 100$. 
FIGS. 5a and b. Follow-up smears: highly abnormal squamous cells. Haematoxylin and eosin $\times 160$.

FIG. 5a.

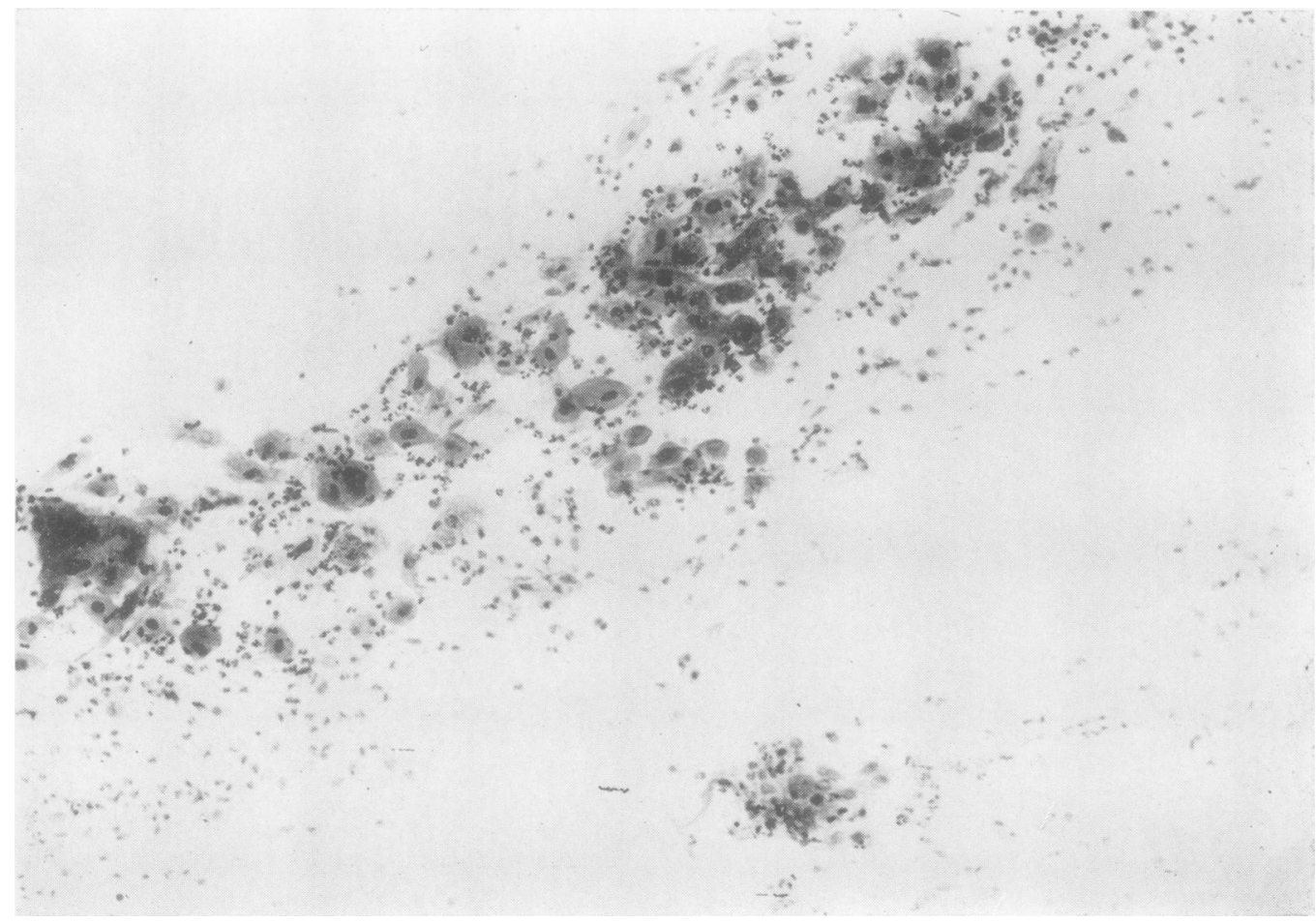

FIG. $5 b$. 


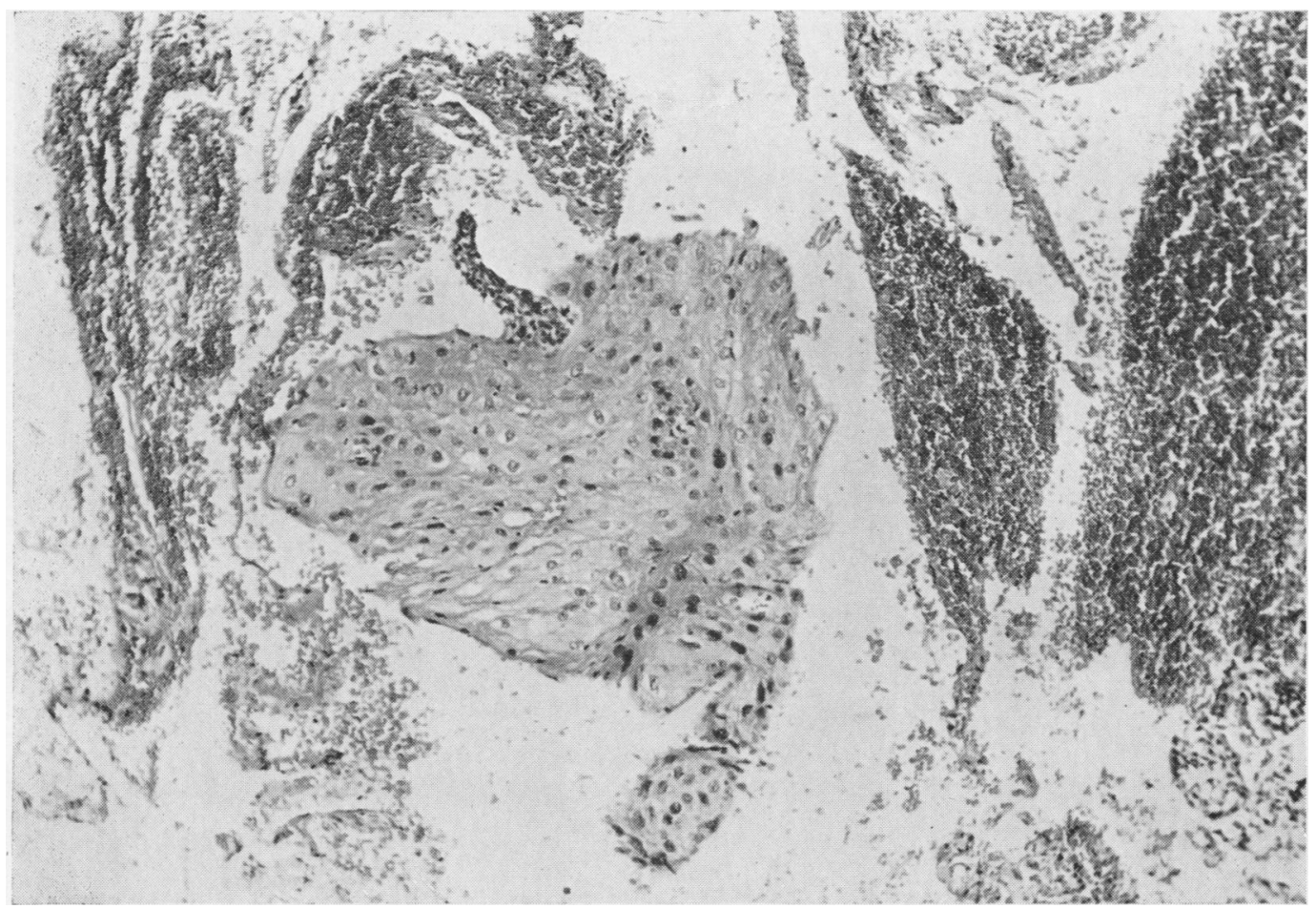

FIG. 0. Secuna curettings: a strip of squamous epithelium with marked nuclear atypia. Haematoxylin and eosin $\times 100$.

such strip (Fig. 2) and columnar epithelium adjacent to an area of squamous epithelium resembling the appearance of adenoacanthosis was present in another piece (Fig. 3). In addition, numerous desquamated squamous cells with marked nuclear atypia were also present. The cone biopsy was about $1.5 \mathrm{~cm}$. tall (after fixation). When sectioned serially, it was found that about $40 \%$ of the surface epithelium was missing from the canal. The squamous epithelium showed a minimal degree of atypia only; in the cervical canal moderately severe chronic inflammatory changes were present, and the epithelium, where present, was columnar (Fig. 4).

SECOND CURETTINGS AND BIOPSIES These consisted of much blood clot and small strips of squamous epithelium with marked nuclear atypia (Fig. 6). Much keratin debris and numerous abnormal desquamated squamous cells were again present. Two pieces of cervical tissue were also examined. These showed chronic inflammatory changes only with a very slight degree of basal cell hyperplasia of the squamous epithelium.

HYSTERECTOMY SPECIMEN The hysterectomy specimen consisted of the uterus and both tubes and ovaries. The uterus measured $7 \mathrm{~cm}$. to the external os; the wall was up to $1.7 \mathrm{~cm}$. thick. The upper twothirds of the entire body were taken up by a buffcoloured firm ulcerating tumour which penetrated the entire thickness of the wall (Fig. 7). The lining of the lower third of the body and of the cervical canal was haemorrhagic and slightly ragged. Recent biopsy incisions were present on the cervix, which was otherwise normal. The tubes and ovaries appeared normal. Five sections from the tumour itself all showed the same appearance, namely, a well-differentiated squamous carcinoma with keratinization (Fig. 8). The tumour cells showed much swelling and vacuolization in places. Nuclear anisocytosis was marked, and karyolysis was present in places. A moderate inflammatory response was evident throughout the stroma, consisting of polymorphs, plasma cells, and lymphocytes. In many places there was evidence of breaking up of tumour cell nests by macrophages and polymorphs, and phagocytosis of tumour cells by giant cells (Fig. 9). No columnar epithelium, either benign or malignant, was present in any section of the tumour. Five sections were cut from the tumour edge and from the remaining endometrial cavity. Extensive coagulation (radium) necrosis had destroyed much of the 

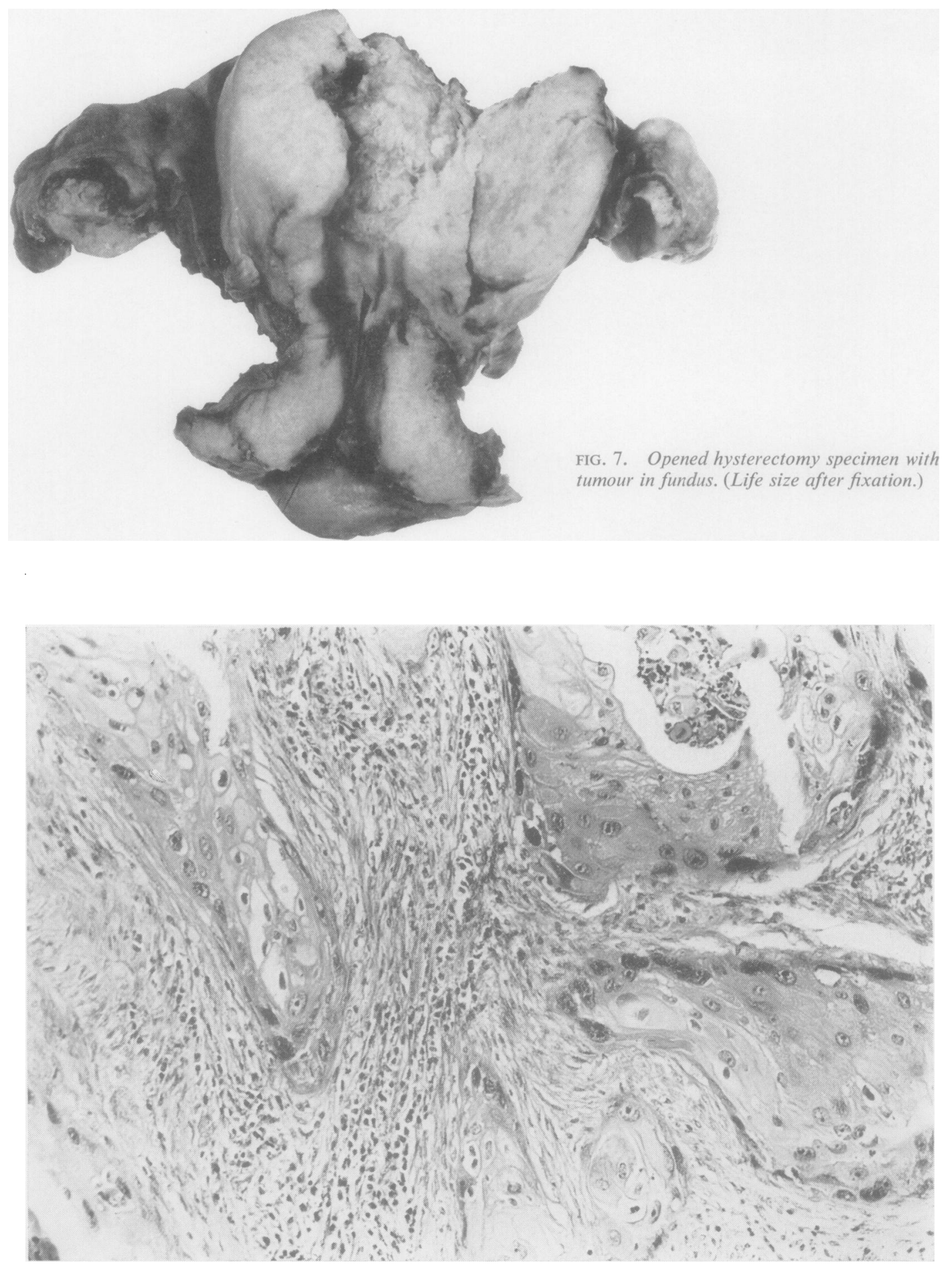

FIG. 8. Section from tumour showing a well-differentiated squamous cell carcinoma. Haematoxylin and eosin $\times 160$. 


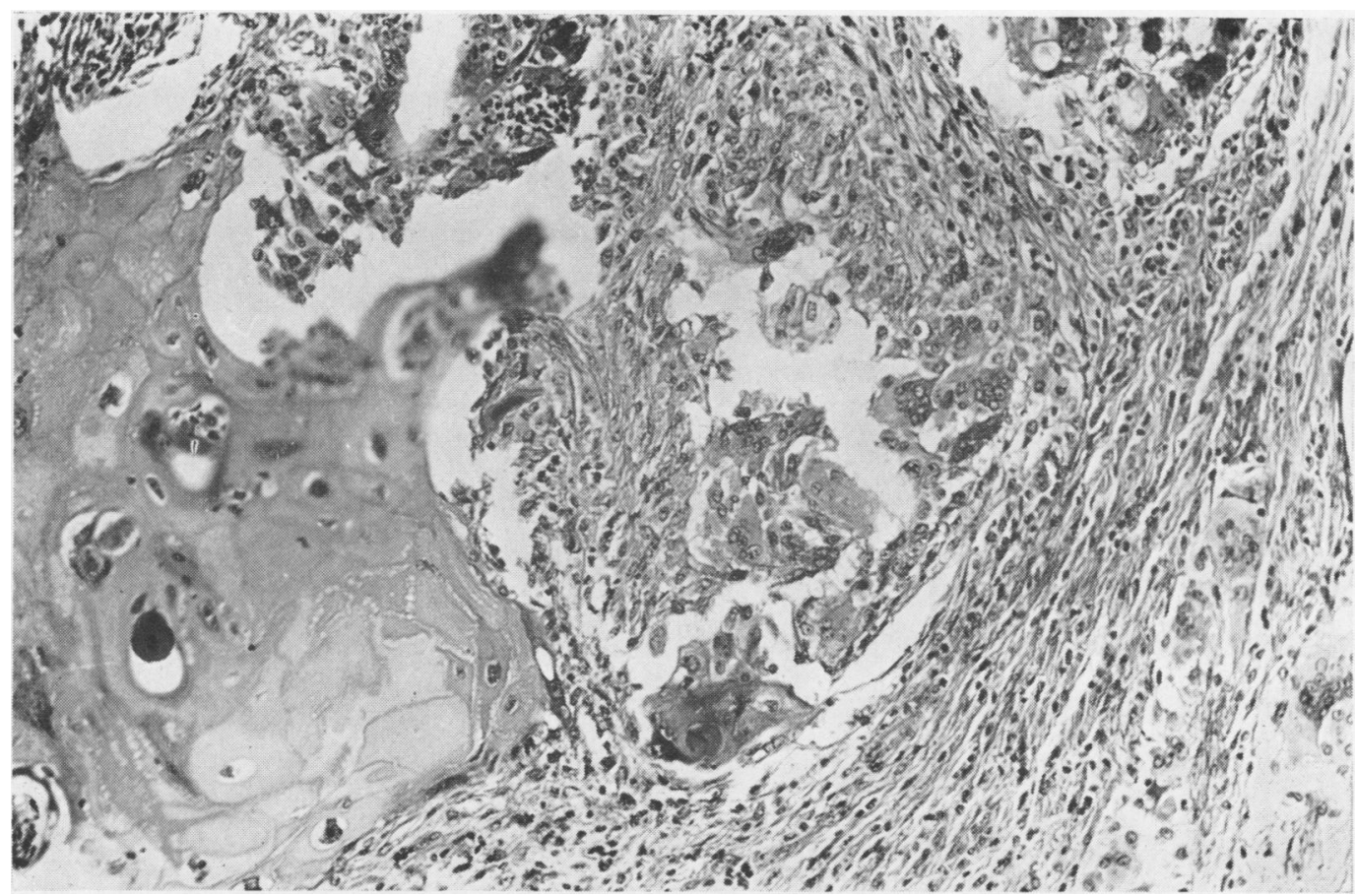

FIG. 9. Section from tumour showing cytoplasmic swelling and vacuolization, as well as oreaking up of tumour cell nests and phagocytosis of tumour cells by giant cells. Haematoxylin and eosin $\times 160$.

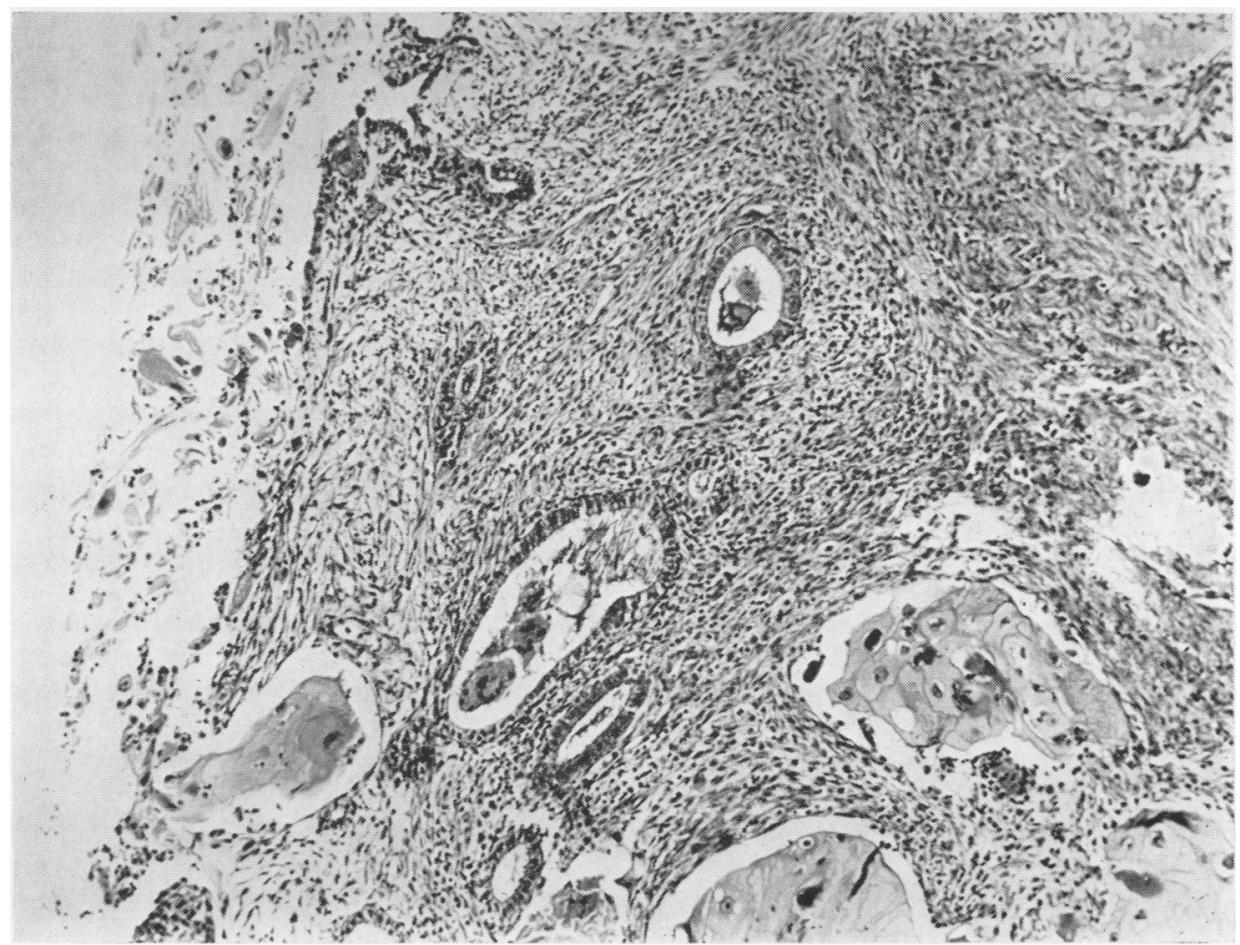

FIG. 10. Section from tumour edge showing adjoining intact endometrial glands. Haematoxylin and eosin $\times 100$. 
surface layers of the entire uterus and cervix. It was, however, possible to demonstrate endometrium with cuboidal epithelium lining the surface and glands in the immediate vicinity of the tumour (Fig. 10) and in several other places. In one section a circumscribed area of squamous epithelium was found merging into cuboidal epithelium on either side on the endometrial surface; cuboidal epithelium was lining the glands beneath this. The lining of the cervical canal, where preserved, was columnar epithelium. No evidence of invasive growth was found in four sections of the cervix. All surface epithelium showed a marked response to radium.

\section{DISCUSSION}

The following points of interest emerge from this case:-

The case presented here is a true primary squamous carcinoma of the body of the uterus. A primary invasive carcinoma of the cervix was ruled out conclusively by serial sectioning of the original cone biopsy, by later cervical biopsies, and finally by multiple sections from the hysterectomy specimen. No coexisting adenocarcinoma was found. In spite of extensive damage to surface layers caused by radium, it was possible to demonstrate columnar epithelium in the cervical canal and cuboidal epithelium on the endometrial surface and in the glands. This uterine tumour was therefore not preceded by a generalized squamous metaplasia of the entire surface epithelium as was described by $\mathrm{Chu}$ et al. (1958) in his case. While much discussion still centres on the problem of the aetiology of squamous metaplasia in the endometrium of adult women (Novak, and Woodruff, 1962), the presence of a squamous cell carcinoma of the body is easier to understand when it appears as a sequel to such a generalized metaplastic process than when it arises apparently de novo. Nor was there in this case any evidence in the hysterectomy specimen of a pre-existing endometrial glandular hyperplasia with acanthosis, which, at least in theory, could give rise to a squamous carcinoma. The origin of this tumour remains therefore problematical. It could be assumed to have arisen in a localized area of squamous metaplasia of surface epithelium, the aetiology of which is unknown. At least one such isolated area of squamous metaplasia was demonstrated.

The swelling of the tumour cells, the occasionally marked nuclear irregularities, as well as the appearance of phagocytosis of tumour cells by macrophages and giant cells (Fig. 9) were all interpreted as the response to radium. This interpretation would explain the apparent dissimilarity between the appearances of the 'atypical' epithelium in both curettings and the appearances of the tumour in the sections. The 'atypical' squamous epithelium in bothcurettings must, in retrospect, be assumed to have originated in the same tumour which was present all along and caused the patient's symptoms.

Finally, while there is no question of the value of vaginal cytology in general, and while it may have कै played a minor role even in this case, it would appear $\overrightarrow{0}$ that on balance cytology-conscious thinking had $\vec{\overrightarrow{ }}$ tended to obscure the real issue. From the appear- $\vec{\omega}$ ances of the first smears a squamous carcinoma of the cervix, or at least a lesion in situ, was suspected.? A negative cone biopsy, from which, however, much $\vec{\oplus}$ surface epithelium was missing, does not exclude a lesion in situ: when curettage precedes conization, $\vec{v}$ accidental scraping of the endocervical canal is often 0 unavoidable. It was reasonable to assume that $a^{\circ}$ carcinoma in situ could have been present in these $z$ denuded areas; the finding of detached strips of very atypical squamous epithelium in the curettings lent $\stackrel{\$}{乛}$ support to this view. These strips of epithelium could 0 not be diagnosed as unequivocally malignant. We $\stackrel{\Phi}{-}$ have become familiar with the very gradual merging $\vec{C}$ of the 'borderline squamous dysplasias' of the of cervix with carcinoma in situ, and the differentiation of one lesion from the other is a highly individual judgment. The appearance of the strips of epithelium in the curettings resembled this type of intermediate lesion. Thus, while an invasive squamous carcinoma $\stackrel{\circ}{\varnothing}$ of the cervix was excluded, the findings in the original $\stackrel{\circ}{\rightarrow}$ smears, in the cone biopsy, and in the curettings 0 could reasonably lead to the diagnosis of 'borderline squamous dysplasia' merging into carcinoma in situ. In previous cases with similar findings such an interpretation has proved correct; however, it was an용 erroneous explanation for the findings presented: here. Had there not been a satisfactory interpretation for these findings, the possibility of a squamous 8 carcinoma of the body of the uterus, however rare, might have been considered more readily.

I wish to thank Dr. A. Gibson for her interest and $\frac{7}{0}$ encouragement and Miss E. Sibthorpe for her assistance in clinical matters and for helpful discussion. I am N indebted to Dr. M. Bennett for permission to use his material from this case. I am deeply grateful to Mr. A. L. N Barron for preparing the photomicrographs and to $N$ Miss K. Hastings for technical assistance.

\section{REFERENCES}

Chu, F., Lepow, H., and Godsick, W. (1958). Arch. Path., 65, 13. Fluhmann, C. F. (1928). Surg. Gynec. Obstet., 46, 309.

Mazzella, G. (1963). Rass, int. Clin. Ter., 43, 613.

Novak, E. R., and Woodruff, J. D. (1962). Gynecologic and Obstetric Pathology, 5th ed., p. 155. Saunders, Philadelphia.

Peris, L. A., Jernstrom, P., and Bowers, P. A. (1958). Amer. J. Obstet. Gynec., 75, 1019.

Wahi, P. N., and Jain, R. L. (1949). Indian J. med. Sci., 3, 417. 